\title{
Duodenal obstruction due to accidental swallowing of a dental prosthesis: a case report and review of the literature
}

\author{
Saadat Mehrabi, Mohammad Javad Yavari Barhaghtalab* and Reza Hosseinpour ${ }^{*}$
}

\begin{abstract}
Background: Artificial dentures are the most common object ingested by elderly patients and account for 4-18\% of all foreign body ingestions. Denture impaction in the small bowel is a rare phenomenon. Surgery of the duodenum is difficult, so endoscopy should be the first choice in these patients. There are very rare case reports on denture ingestion-induced duodenal obstruction or perforation, so the aim of this publication was to show a rare case of accidental ingestion of a dental prosthesis with duodenal obstruction and also perforation that could not be treated with endoscopic management and was managed with duodenal kocherization and gastrostomy.

Case presentation: A 47-year-old Iranian woman presented to our hospital with epigastric abdominal pain of 2 hours' duration after the accidental ingestion of a dental prosthesis 2 days before admission. The patient had severe epigastric tenderness. Radiographic examination revealed nothing. Upper gastrointestinal endoscopy showed a swallowed lodged denture in the second to third parts of the duodenum, and the attempt to extract the denture failed. The patient underwent laparotomy and duodenal kocherization, pushing the denture to the stomach, and gastrostomy, and the denture was brought out without any complications.

Conclusions: Patients with old and worn dentures should have their prosthesis reconstructed and redesigned periodically in order to prevent denture ingestion and its complications. Early surgical intervention is recommended in patients with failed endoscopic extraction of foreign bodies and in those with duodenal perforation.
\end{abstract}

Keywords: Artificial denture, Duodenal obstruction, Perforation, Endoscopy, Gastrostomy

\section{Background}

Ingested foreign bodies progress through the digestive tract spontaneously in $80-90 \%$ of cases; however, 10 $20 \%$ of patients require endoscopy for removal, and less than $1 \%$ undergo surgery [1]. Ingested foreign bodies are commonly seen in patients with alcohol overuse and drug misuse due to impaired judgment; emotional disturbance; psychiatric disorders such as schizophrenia, mental retardation, and Alzheimer disease; and in persons who wear artificial dentures [2].

\footnotetext{
* Correspondence: mj.yavari.barhaghtalab@gmail.com;

reza.hosseinpour@yums.ac.ir

Department of General Surgery, Shahid Beheshti Hospital, Yasuj University of Medical Sciences, Yasuj, Iran
}

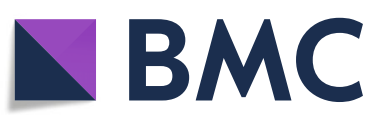

(c) The Author(s). 2020 Open Access This article is licensed under a Creative Commons Attribution 4.0 International License, which permits use, sharing, adaptation, distribution and reproduction in any medium or format, as long as you give appropriate credit to the original author(s) and the source, provide a link to the Creative Commons licence, and indicate if changes were made. The images or other third party material in this article are included in the article's Creative Commons licence, unless indicated otherwise in a credit line to the material. If material is not included in the article's Creative Commons licence and your intended use is not permitted by statutory regulation or exceeds the permitted use, you will need to obtain permission directly from the copyright holder. To view a copy of this licence, visit http://creativecommons.org/licenses/by/4.0/ The Creative Commons Public Domain Dedication waiver (http://creativecommons.org/publicdomain/zero/1.0/) applies to the data made available in this article, unless otherwise stated in a credit line to the data. 


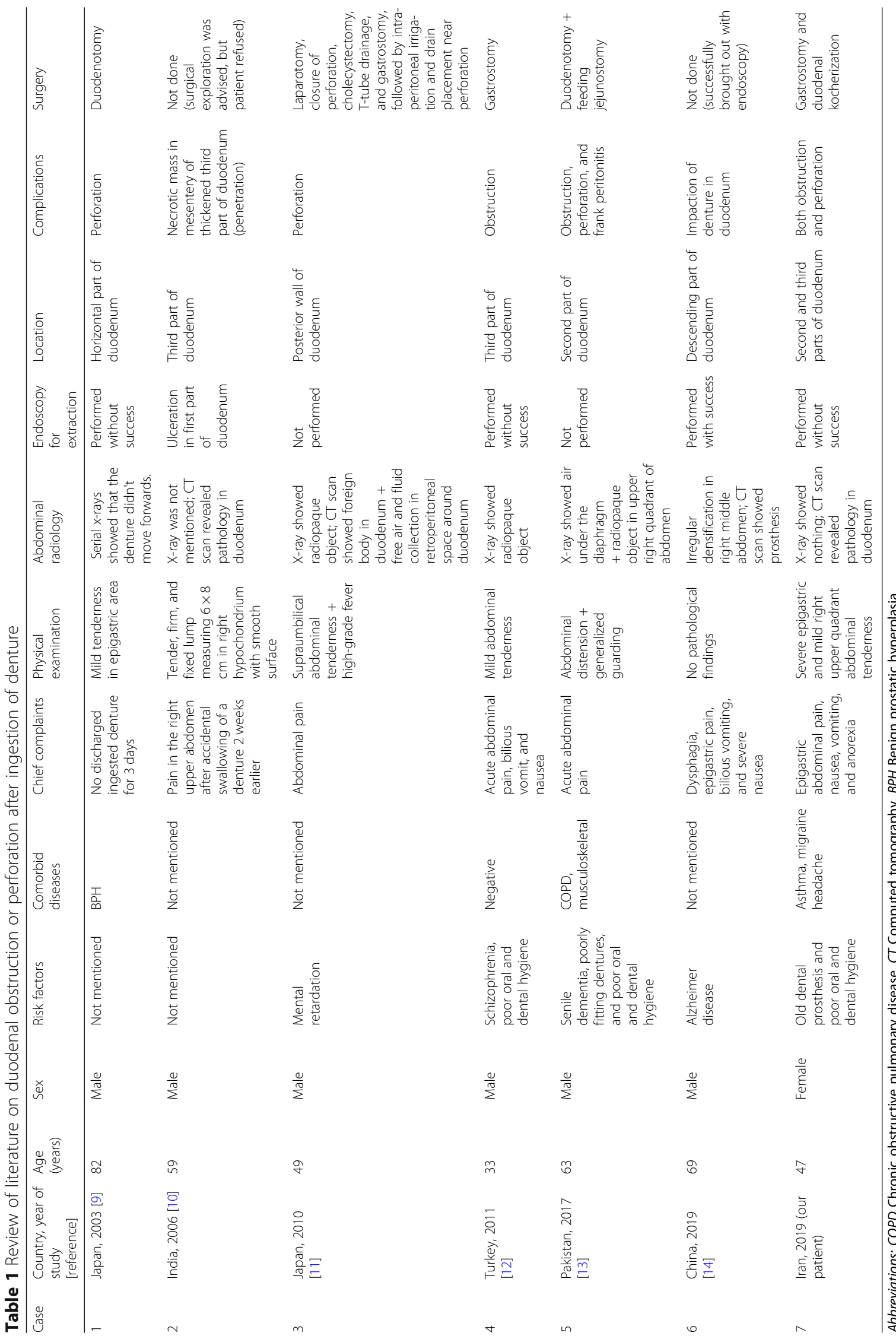


or blind segments [6]. Endoscopy can be used for the extraction of swallowed artificial dentures, but in a number of cases, endoscopy fails, which leads the physician to plan surgical exploration and removal $[7,8]$.

There are very rare case reports on denture ingestioninduced duodenal obstruction and perforation, and we found six previous reports to use in our review of the literature, as shown in Table 1 [9-14]. The aim of this study was to report a rare case of accidental ingestion of a dental prosthesis with duodenal obstruction and perforation that could not be treated with endoscopic management and was managed with duodenal kocherization and gastrostomy.

\section{Case presentation}

A 47-year-old Iranian woman presented to our hospital with the chief complaint of pain in the abdomen (mostly in the epigastric area) for the previous 2 days, associated with recurrent vomiting, nausea, and anorexia. Her complaints had started 2 hours after the accidental ingestion of a dental prosthesis about 2 days before admission (Fig. 1). The patient has a known history of asthma and migraine headache and a history of wearing artificial dentures. At the time of admission, she was conscious and oriented to time, place, and person. Her pulse rate was 90 beats per minute, and her blood pressure was 100/60 mmHg. Her physical examination revealed severe epigastric and mild right upper quadrant abdominal tenderness.

A radiograph showed no free gas under the right dome of the diaphragm and no air-fluid level (Fig. 2). Ultrasonography revealed that there was no free fluid in the peritoneal cavity. Spiral abdominal computed tomography (CT) with oral and intravenous contrast revealed duodenal wall thickness in D2-4, peripheral mesenteric fat edema, hematoma in D1-3, air in the intestinal wall,

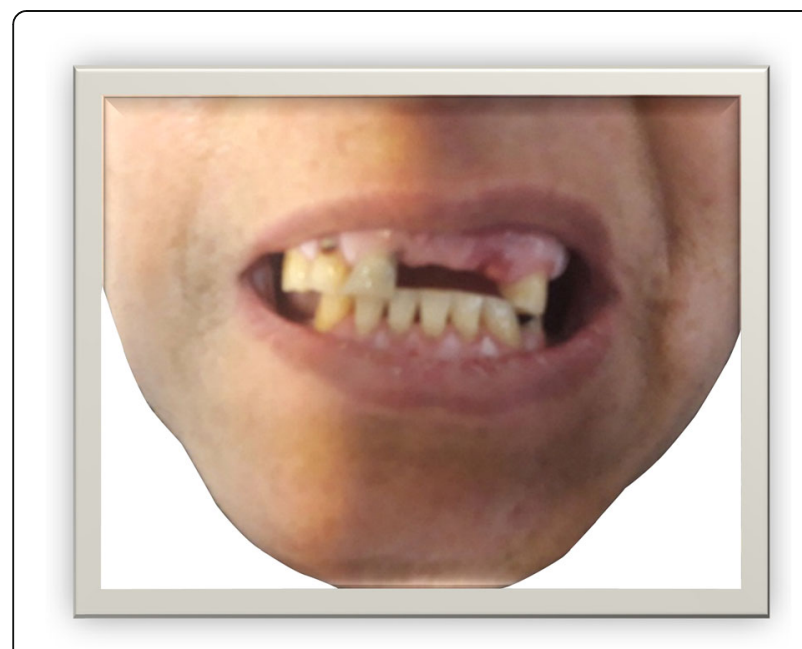

Fig. 1 Picture of our patient with loss of upper anterior dentures

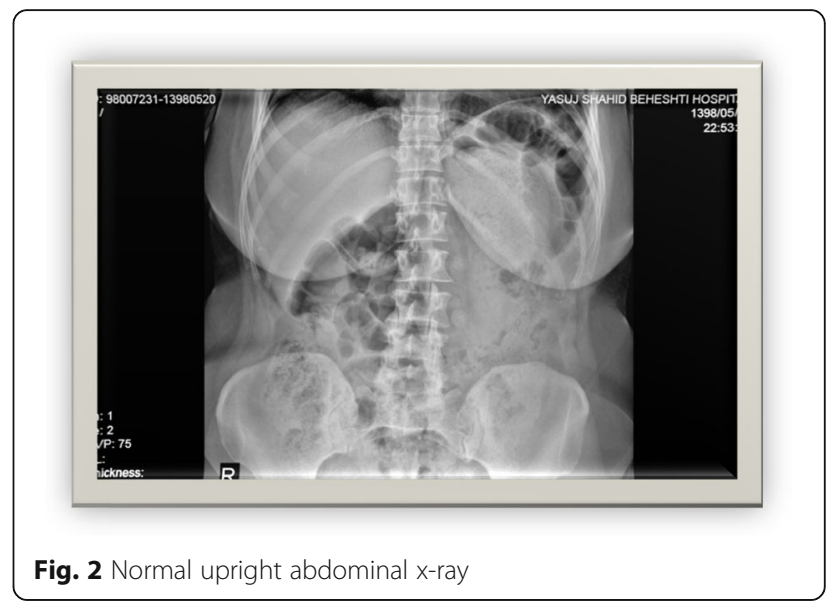

pneumoretroperitoneum, laceration in D1-2 and a part of D3, and microperforations in D2-3. Because of the hematoma, narrowing in the primary and middle parts of the duodenum was seen (Figs. 3 and 4).

Video endoscopic findings were an old healed linear ulcer scar in the bulb of the duodenum, and also a swallowed lodged denture was seen in D2-3 after a papilla, which left a laceration behind. An attempt to capture the foreign body was not possible because of difficulty in the procedure and the chance of induced laceration, so a gastroenterologist recommended surgical evacuation of the denture. Laboratory investigation results are shown in Table 2.

After preparation of the operation site, a midline laparotomy was performed. The stomach and small bowel were examined carefully for any perforation, but no pathology was revealed; however, a foreign body was palpable between the second and the third portions of the duodenum inside the lumen, so duodenal kocherization was performed to explore the duodenum for any

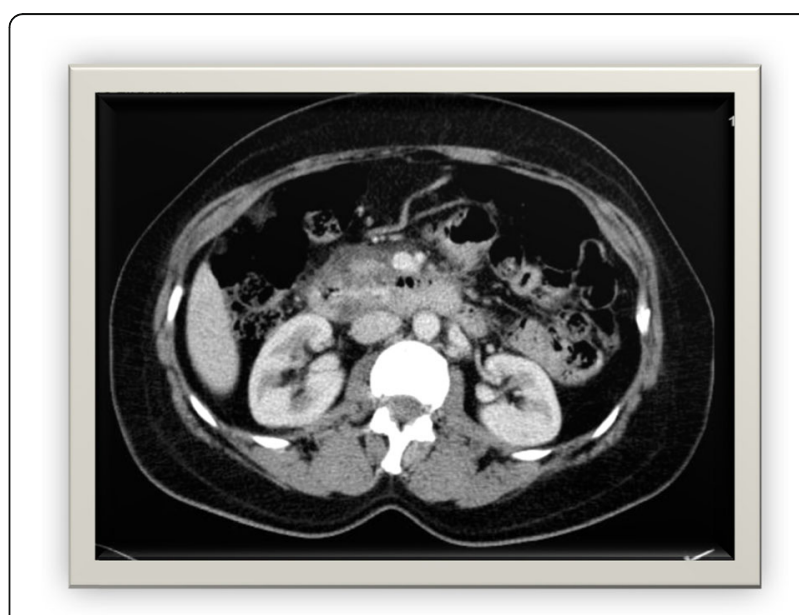

Fig. 3 Wall thickness, peripheral mesenteric fat edema, hematoma, and narrowing of the duodenum 


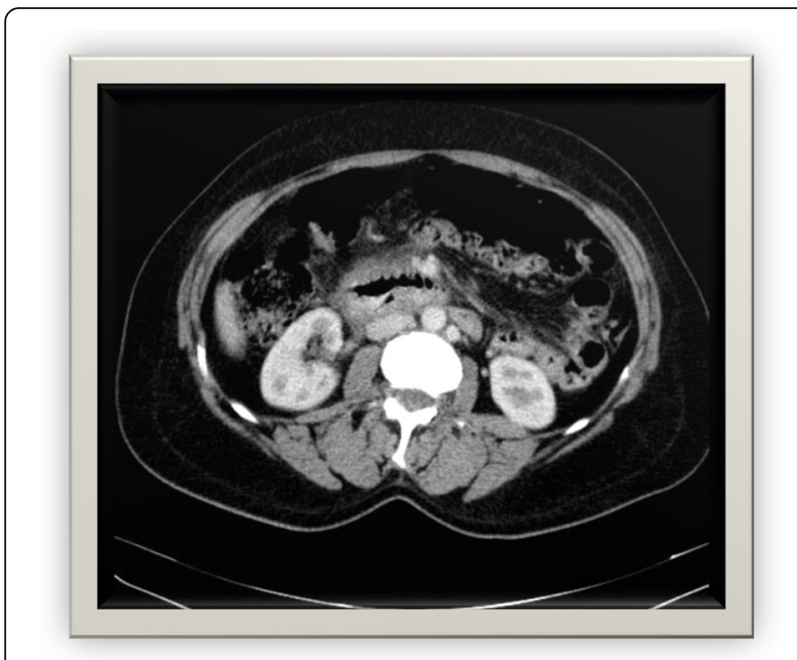

Fig. 4 Air in intestinal wall, pneumoretroperitoneum, laceration, and microperforations in the duodenum

perforations. There was no gross perforation in the duodenal wall, so the foreign body was pushed through the lumen to pass back to the stomach from the pylorus. A gastrostomy was performed, and the foreign body was removed and identified as an artificial denture (Fig. 5). Then the stomach was repaired in two layers. Washing with normal saline was done, and an abdominal drain was placed at the duodenal site of kocherization. The patient recovered well postoperatively and was discharged on the ninth day of her total hospitalization in good condition.

\section{Discussion and conclusions}

Most reported cases of accidental swallowing of dentures are related to food ingestion [13]. The anatomic sites of obstruction in descending order are the upper esophageal sphincter (cricopharyngeal area), the aortic arch, the lower esophageal sphincter (diaphragmatic hiatus), the pylorus, and the ileocecal valve $[15,16]$. Once the object reaches the stomach, it can continue to pass through to the ileocecal region almost without difficulty [4].

Table 2 Laboratory findings in our patient

\begin{tabular}{|c|c|}
\hline Laboratory results & Normal range \\
\hline$\overline{\text { WBC } 12,500 / \mathrm{mm}^{3}}$ & $4300-10,800$ cells $/ \mathrm{mm}^{3}$ \\
\hline Hemoglobin $10.9 \mathrm{~g} / \mathrm{dl}$ & Female: $12.1-15.1 \mathrm{~g} / \mathrm{dl}$ \\
\hline Platelets $254,000 / \mu l$ & $150,000-400,000$ platelets/ $\mu \mathrm{l}$ \\
\hline Serum amylase $35 \mathrm{U} / \mathrm{L}$ & $30-110 \mathrm{U} / \mathrm{L}$ \\
\hline Blood sugar $98 \mathrm{mg} / \mathrm{dl}$ & $<140 \mathrm{mg} / \mathrm{dl}$ \\
\hline Serum creatinine $0.88 \mathrm{mg} / \mathrm{dl}$ & $0.7-1.2 \mathrm{mg} / \mathrm{dl}$ \\
\hline Blood urea nitrogen $10 \mathrm{mg} / \mathrm{dl}$ & $7-20 \mathrm{mg} / \mathrm{dl}$ \\
\hline Urine examination & Normal \\
\hline
\end{tabular}

WBC White blood cells, cells $/ \mathrm{mm}^{3}$ Cells per cubic millimeter, g/dL Grams per deciliter, U/L Units per liter, $m g / d$ l Milligrams per deciliter

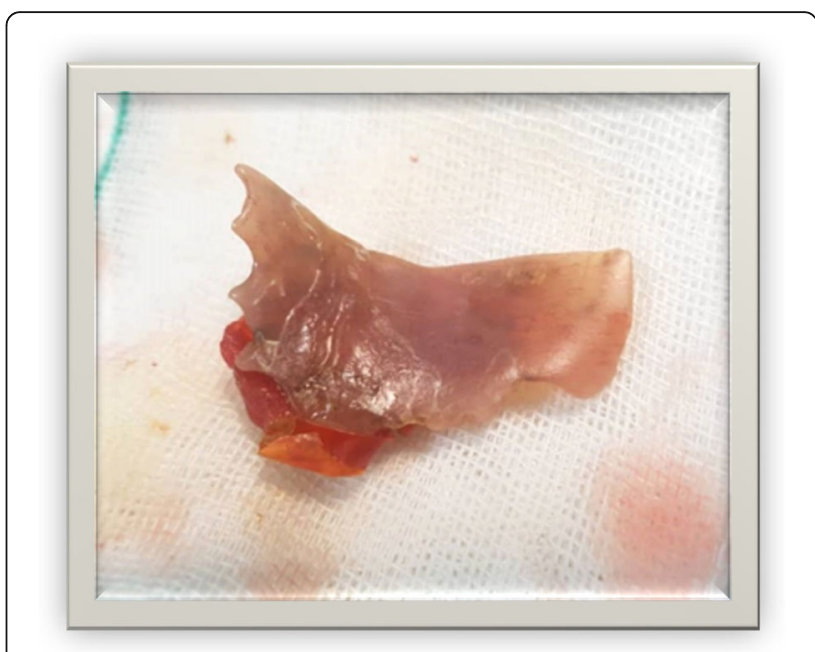

Fig. 5 Artificial teeth (radiolucent plastic part known as the polymethylmethacrylate part) with two sharp and two blunt edges and a portion of food material (tomato) attached behind

Denture impaction in the small bowel is a rare phenomenon [4]. The passage through the duodenum depends on the diameter as well as the length of the ingested foreign body. Foreign bodies with lengths more than $6 \mathrm{~cm}$ and diameters more than $2.5 \mathrm{~cm}$ pass the duodenum with difficulty [3]. The base of an artificial denture is made of a radiolucent plastic material known as polymethylmethacrylate (Fig. 5), whereas the tooth is made of porcelain. The radiopaque area of a denture is the metal pin that holds it together. A multiplanar CT scan is the preferred choice to identify the exact location of radiolucent dentures [13]. A dislodged swallowed denture usually presents within a few days and can be followed successfully passing through the GI tract to the rectal canal by serial radiological investigations [13]. If an object remains motionless for 3 days in the intestine or for 1 week in the stomach, surgery is required [17]. Surgery of the duodenum is difficult, so endoscopy should be the first choice for patients in whom a foreign object is demonstrated to be fixed in the upper GI system. In cases in which endoscopic extraction fails, surgery should be considered [12].

In our patient's case, endoscopy failed to bring out the swallowed denture, which led us to perform surgical exploration and removal. Our review of the literature on duodenal obstruction or perforation after ingestion of dentures found six previous studies. Table 1 provides a summary of specific characteristics of these studies and also our present case report, including demographic and risk factors, chief complaints, physical examinations, abdominal radiological findings, endoscopy for extraction of the denture if done, location of obstruction or perforation, and kind of surgery. According to our report and the six previous reports mentioned [9-14], if there is evidence of duodenal perforation or if the endoscope is 
unable to remove the foreign body early, surgical intervention is recommended.

Our present case report is different from other case reports in the literature according to the patient's sex; our patient was female, but none of the earlier cases reported were female. Our patient had both obstruction and perforation, similar to the patient in the Siddiq et al. [13] study, but our patient's case was comparable to other case reports in which only one of obstruction, perforation, impaction, and penetration was the dominant pathology [9-14]. This process might be due to excessive dilation of the duodenum due to the progression of bowel obstruction, which results in fragility of the intestinal wall and leads to perforation and even the generation of peritonitis [18].

Artificial dentures are the most common object ingested by elderly patients. However, there have been reports that accidental ingestion of foreign bodies is increasing because of an aging society in recent years, and accidental ingestion of dentures has increased by about twofold. The larger and sharper the denture, the more complications occur. In cases in which endoscopic extraction fails, surgery should be considered. During surgery, attention must be paid not to harm the duodenum. Patients with old and worn dentures should have their prostheses reconstructed and redesigned periodically in order to prevent denture ingestion and its complications. Early surgical intervention is recommended in patients with failed endoscopic extraction of foreign bodies and in those with duodenal perforation.

\section{Abbreviations \\ CT: Computed tomography; Gl: Gastrointestinal; WBC: White blood cells}

\section{Acknowledgements}

We express our gratitude to the patient, who kindly gave consent for her case to be presented in this paper. We also thank Dr. Aida Iraji at the central research laboratory of Shiraz University of Medical Sciences for her assistance in editing the manuscript.

\section{Authors' contributions}

SM and $\mathrm{RH}$ evaluated the patient clinically, operated on the patient (as main surgeons), and revised the manuscript. MJYB evaluated the patient clinically, helped to operate on the patient (as co-surgeon), reviewed the literature, and prepared the manuscript. All authors read and approved the final manuscript.

\section{Funding}

None received.

\section{Availability of data and materials}

All data generated or analyzed during this study are included in this article.

\section{Ethics approval and consent to participate}

Written informed consent was obtained from the patient for publication of this case report and any accompanying images. A copy of the written consent is available for review by the Editor-in-Chief of this journal.

\section{Consent for publication}

Approved publication or whether approval for publication was sought and received.

\section{Competing interests}

The authors declare that they have no competing interests.

Received: 11 September 2019 Accepted: 15 July 2020

Published online: 15 August 2020

\section{References}

1. Magalhães-Costa P, Carvalho L, Rodrigues JP, Túlio MA, Marques S, Carmo J, et al. Endoscopic management of foreign bodies in the upper gastrointestinal tract: an evidence-based review article. GE Port J Gastroenterol. 2015;23(3):142-52. https://doi.org/10.1016/j.jpge.2015.09.002.

2. Zarei $M$, Shariati $B$, Bidaki R. Intestinal perforation due to foreign body ingestion in a schizophrenic patient. Int J High Risk Behav Addict. 2016;5(3): e30127. https://doi.org/10.5812/ijhrba.30127.

3. Ambe P, Weber SA, Schauer M, Knoefel WT. Swallowed foreign bodies in adults. Dtsch Arztebl Int. 2012;109(50):869-75. https://doi.org/10.3238/ arztebl.2012.0869.

4. Gachabayov M, Isaev M, Orujova L, Isaev E, Yaskin E, Neronov D. Swallowed dentures: two cases and a review. Ann Med Surg (Lond). 2015;4(4):407-13. https://doi.org/10.1016/j.amsu.2015.10.008.

5. Akelma H, Salik F, Başol Ö, Bilge H, Yıldırım A, Özgün Ş. Ingestion of partial denture after general anesthesia induction and ventilation: a rare case report. Case Rep Surg. 2019;2019:8726508. https://doi.org/10.1155/2019/ 8726508.

6. Tsai C-Y, Hsu C-C, Chuah S-K, Chiu K-W, Changchien C-S. Endoscopic removal of a dental prosthesis in the hepatic flexure of the colon. Chang Gung Med J. 2003;26(11):843-6

7. Singh $P$, Singh A, Kant $P$, Zonunsanga B, Kuka AS. An impacted denture in the oesophagus-an endoscopic or a surgical emergency-a case report. J Clin Diagn Res. 2013;7(5):919-20. https://doi.org/10.7860/JCDR/2013/5337.2976.

8. Boopathy V, Bakshi SS, Balasubramanian P, Dakshinamoorthy S. Neglected partial denture in the lower oesophagus presenting after 7 days. BMJ Case Rep. 2015;2015:bcr2015211400. https://doi.org/10.1136/bcr-2015-211400.

9. Yutaka T, Hiroshi I, Mituo K, Sadaaki K, Masanobu M, Toshitaka F. A case of duodenum perforation following ingestion of a partial denture [in Japanese]. Showa Igakkai Zasshi. 2003;63(4):443-6. https://doi.org/10.14930/ jsma1939.63.443.

10. Sahu S, Burathoki S, Bahl D, Sachan P. Foreign body erosion of duodenum. Internet J Surg. 2006;13(2):1-4.

11. Okuyama K, Hiraki M, Ohtsuka T, Miyoshi A, Noshiro H, Miyazaki K. A case of duodenal perforation caused by a partial denture in a patient with mental retardation [in Japanese]. Nihon Rinsho Geka Gakkai Zasshi. 2010;71(7):17858. https://doi.org/10.3919/jjsa.71.1785.

12. Yilmaz M, Akbulut S, Ozdemir F, Gozeneli O, Baskiran A, Yilmaz S. A swallowed dental prosthesis causing duodenal obstruction in a patient with schizophrenia: description of a new technique. Int J Surg Case Rep. 2012; 3(7):308-10. https://doi.org/10.1016/j.jijscr.2012.03.031

13. Siddiq M, Qureshi AU, Faroog MS, Ali AA. Duodenal perforation due to ingested partial denture. J Coll Physicians Surg Pak. 2017;27(12):778-9.

14. Ouzhu M, Wu C, Ye L, Dawa J, Hu B. Endoscopic removal of dental prosthesis impacted in the duodenal papilla. Endoscopy. 2019;51(01):10-1. https://doi.org/10.1055/a-0756-7236.

15. Mumoli N, Busoni A, Cei M. A swallowed denture. Lancet. 2009;373(9678): 1890. https://doi.org/10.1016/S0140-6736(09)60307-X.

16. Santander-Flores SA, Mata-Quintero CJ, O'Farrill-Anzures R, González-Villegas P, Calvo-Vázquez I, Campos-Serna El. Accidental ingestion of dental prostheses; 2 scenarios in the management and outcome. Case reports. Cir Cir. 2017;85(4):350-5. https://doi.org/10.1016/j.circen.2017.07.002.

17. da Costa MA, Maia LGM, Jacob HB, Junior LGG. Accidental swallowing of orthodontic expansion appliance key. Am J Orthod Dentofac Orthop. 2011; 140(2):266-8. https://doi.org/10.1016/j.ajodo.2011.05.009.

18. Toledo JS Jr, Correia MM, Coutinho RR, Kifer EF, Torres DFM. Perforation of the cecum resulting from a closed-loop obstruction in a patient with an adenocarcinoma of the sigmoid colon: a case report. Int J Surg Case Rep. 2017;36:143-6. https://doi.org/10.1016/j.jiscr.2017.05.021.

\section{Publisher's Note}

Springer Nature remains neutral with regard to jurisdictional claims in published maps and institutional affiliations. 